\title{
Censura y autocensura en la cobertura de temas relacionados al narcotráfico y la delincuencia organizada en el Estado de Sonora, México
}

\author{
MHC) n 6 | Año 2015 \\ Artículo 으 6 (67) \\ Páginas 129 a 160 \\ mhcj.es
}

\author{
M. C. Joaquín Andrés Félix Anduagal jfelix@ sociales.uson.mx \\ Universidad de Sonora \\ L.C. Eliana Alvarado Noriega| eliana.alvarado01@gmail.com \\ Periodista e investigadora \\ L.C. Lin Mendívil Alvarado.| linmendivil@ admvos.uson.mx \\ Universidad de Sonora.
}

\section{Palabras clave}

Periodismo, narcotráfico, impunidad, autocensura, censura, M éxico, Sonora

Sumario

1. Introducción.

\section{Metodología}

3. Resultados. 3.1 La fuente policiaca. 3.2 Censura y autocensura. 3.2.1. Variantes de la censura. 3.2.2 Autocensura. Difundir solo lo necesario, aun contando con la información disponible 3.3 La empresa y el gremio periodístico 3.3.1. La mejora de condiciones laborales 3.3.2. Capacitación 3.3.3. Estar unidos 3.3.4. Los retos

4. Discusión y conclusiones

5. Referencias bibliograficas

6. Notas

\section{Resumen}

En México, cada dos días un comunicador sufre algún tipo de agresión. Así lo señala el Centro de Periodismo y Ética Pública (Cepet), según el cual en 2010 se registraron 139 casos de periodistas amenazados, privados de su libertad o asesinados. No es casual que México sea considerado el país más peligroso de América Latina para ejercer el periodismo. El crimen organizado no respeta cargos: reporteros, fotógrafos, camarógrafos, editores y directivos corren el riesgo de ser objeto de represalias.

A nivel nacional el estado de Sinaloa se considera el más peligroso para los periodistas, sin embargo, estados fronterizos del norte, como Sonora, también son de alto riesgo. A partir de conocer esta situación, se identificó a un grupo de 24 periodistas de tres municipios clave en el estado (Hermosillo, Nogales y Ciudad O bregón), a quienes se les aplicó entrevistas a profundidad y otros participaron en grupos focales. También se han consultado expertos nacionales e internacionales en el tema. La recopilación de los avances aquí presentados se realizó durante 2011, 2012 y 2013.

Hasta el momento, los resultados arrojan que existe temor por parte del gremio periodístico para la publicación de investigaciones relacionadas con el narcotráfico, producto de la falta de garantías del Estado mexicano y de las empresas periodísticas. De acuerdo a los consultados, no hay una estrategia clara para la protección y capacitación de reporteros en coberturas de alto riesgo, quienes advierten un estado de indefensión. Existe entonces en Sonora, al igual que en otras entidades, silencio 0 indiferencia en este tipo de coberturas, lo que provoca una visión difusa 0 inexistente de esta realidad, con el consiguiente menoscabo a la libertad de expresión y el desarrollo a la sociedad.

\section{Forma de citar este artículo en las bibliografías}

Joaquín Andrés Félix Anduaga,. Eliana Alvarado Noriega y Lin Mendívil Alvarado (2015): “Censura y autocensura en la cobertura de temas relacionados al narcotráfico y la delincuencia organizada en el Estado de Sonora, México", en Miguel Hernández Communication Journal, no6, páginas 129 a 160. Universidad Miguel Hernández, UMH (ElcheAlicante). Recuperado el _- de de 20 _- de: [ink del artículo en mhjournal.org] 


\section{Censorship and self-censorship in the coverage of issues related to drug trafficking and organized crime in the State of Sonora, Mexico}

M HCJ n 6 | Year 2015

Paper no 6 (67)

Pages 129 to 160

mhcj.es

\author{
M. C. Joaquín Andrés Félix Anduagal jfelix@ sociales.uson.mx \\ Universidad de Sonora \\ L.C. Eliana Alvarado Noriega| eliana.alvarado01@ gmail.com \\ Periodista e investigadora \\ L.C. Lin Mendívil Alvarado.| linmendivil@ admvos.uson.mx \\ Universidad de Sonora.
}

\section{Keywords}

Journalism, drug trafficking, impunity, selfcensorship and censorship

Sumary

1. Introduction.

2. Methodology.

3. Results. 3.1 The police source. 3.2 Censorship and self-censorship. 3.2.1. Variants of censorship. 3.2.2 Selfcensorship. Spread just enough, even with the information available 3.3 The company and the journalists' union 3.3.1. Improving working conditions 3.3.2. Training 3.3.3. Be united. 3.3.4. The challenges

4. Discussion and conclusion

5. Bibliography.

5. Notes.

\section{Abstract}

In Mexico, every two days a journalist suffers some kind of aggression. This is indicated in the Centro de Periodistas y Ética Pública (Center of Journalists and Public Ethics), according to whom there where 139 cases registered in 2010 of journalists who were threatened, deprived of their freedom or murdered. It's not casual that Mexico is considered as the most dangerous country in Latin America to practice journalism. Organized crime does not respect charge/ titles: journalists, photographers, camera people, editors and managers are at risk of being the object of retaliation.

Nationally, the state of Sinaloa is considered the most dangerous for journalists, however, states in the northern border, like Sonora, are also high risk. From knowing this information, a group of 24 journalists was identified in 3 key municipalities of the state (Hermosillo, Nogales and Cajeme), to whom an interview was applied, and others participated in focus groups. National and international experts in the topic have also been consulted. The collection presented here advances were made during 2011, 2012 and 2013.

So far, the results show that there is a fear in the joumalistic guild for the publication of investigations regarding drug traffic, product of the shortcomings in terms of guarantees from the Mexican State and journalistic companies. According to the people consulted, there is no clear strategy for the protection and training of reporters in high risk coverage, who note a state of defenselessness. In Sonora, just as in other entities, there is silence or indifference in these kind of media coverage, which provokes a diffuse or non-existent vision of this reality, which constitutes an impairment of freedom of expression and the development of society.

\section{How to cite this paper in bibliographies}

Joaquín Andrés Félix Anduaga,. Eliana Alvarado Noriega y Lin Mendívil Alvarado (2015): "Censura y autocensura en la cobertura de temas relacionados al narcotráfico y la delincuencia organizada en el Estado de Sonora, México", en Miguel Hemández Communication Journal, no6, páginas 129 a 160. Universidad Miguel Hernández, UMH (Elche-Alicante). Recuperado el _- de de 20 de: [link del artículo en mhjournal.org] 


\section{Introducción}

Censura y autocensura en la cobertura de temas relacionados al narcotráfico y la delincuencia organizada en el estado de Sonora, México, es una investigación realizada por integrantes del Área Editorial de la Licenciatura en Ciencias de la Comunicación de la Universidad de Sonora, con el objetivo de conocer el estado actual del ejercicio periodístico en temas considerados de alto riesgo en esta entidad de la frontera norte de la República Mexicana. El trabajo que a continuación se expondrá ha sido presentado en el Primer Congreso sobre Estudios de Periodismo, celebrado en Santiago de Chile en junio de 2012; en el Encuentro Nacional Coneicc, realizado en Monterrey, Nuevo León, en marzo de 2013, así como en eventos regionales de comunicación celebrados en la Universidad de Sonora y la Universidad Kino.

Este proyecto es meramente de corte cualitativo, aunque para poder contextualizar y dimensionar la situación del crimen organizado y su relación con el ejercicio periodístico que se vive en el estado de Sonora, región fronteriza ubicada a casi dos mil kilómetros al noroeste de la Ciudad de México, fue necesario recurrir a diversos datos estadísticos, arrojados por instancias certificadas como: la Procuraduría General de la República, la Comisión Nacional de D erechos Humanos, Reporteros sin fronteras, el Centro de Periodismo y Ética Pública, y otros. A partir de conocer la situación que se vive en el noroeste del país, fue preciso identificar a un grupo de periodistas de tres municipios clave en el estado de Sonora, para dar sustento al proceso de investigación, a quienes se les aplicó entrevistas a profundidad, cuestionarios, y otros participaron en grupos focales.

Hasta el momento, los resultados obtenidos producto de la investigación arrojan que en el estado fronterizo de Sonora existe temor por parte del gremio periodístico para la publicación de investigaciones relacionadas con el narcotráfico y la delincuencia organizada, producto de la falta de garantías por parte del Estado mexicano y de las empresas periodísticas.

En México, cada dos días un comunicador sufre de algún tipo de agresión. Así lo señala el Centro de Periodismo y Ética Pública (CEPET), según el cual en 2010 se registraron 139 casos de periodistas que han sido amenazados, despojados de su equipo, privados de su libertad o asesinados. No es casual que México sea considerado el país más peligroso de América Latina para ejercer el periodismo.

El 11 de diciembre de 2006, a diez días de haber tomado el cargo como presidente de México, Felipe Calderón Hinojosa declaró abiertamente la guerra al narcotráfico, situación que al final de su sexenio dejó más 100 mil muertos en todo el territorio nacional; entre las víctimas, estudiantes, niños, mujeres, empresarios, activistas sociales y periodistas, etc. ${ }^{1}$ Por lo anterior, el Comité para la Protección de los Periodistas (CPJ) calificó al sexenio de Felipe Calderón como unos de los periodos más violentos para la prensa que se hayan registrado en el mundo. El conteo del organismo revela 12 reporteros desaparecidos, 14 muertos, octavo 
en el índice de impunidad de la CPJ, así como seis medios de comunicación atacados con carro bomba (1), granada (2), artefacto explosivo (2), armas de fuego (1) y con incendio premeditado $(1)^{2}$.

Así ilustra esta situación Raymundo Riva Palacio en el Manual para un nuevo periodismo:

"Nuevas dinámicas se incorporaron a los medios de comunicación mexicanos durante el gobierno de Felipe Calderón, que inició una lucha contra los cárteles de la droga y la convirtió en el eje de su administración en términos estratégicos, presupuestales y de comunicación. En esta materia, la guerra contra las drogas y el problema de inseguridad en México convirtió a las primeras planas de los periódicos y los noticieros de televisión en registro permanente de sangre y violencia, cuyo torbellino provocó enorme confusión y mostró las contradicciones y antagonismo en los medios, particularmente los impresos" ${ }^{3}$.

El contexto internacional abona en la situación imperante en nuestro país, según lo expone Viridiana Ríos: "Los asesinatos de periodistas siguen un patrón bastante claro. A medida que el tráfico de drogas ha migrado de Colombia a México, el número de periodistas asesinados ha disminuido en el primer país y aumentado en el segundo. De 1997 a 2003, Colombia experimentaba cerca de 9 asesinatos de este tipo al año y México menos de uno. De 2004 a 2010 la tendencia se invirtió. De hecho, desde 2004 México se ha convertido en el país más peligroso para el ejercicio del periodismo de toda Latinoamérica" ${ }^{4}$.

En México, durante el 2012 fueron asesinados seis periodistas, esto según datos del Barómetro de libertad de prensa de la Asociación Internacional no Gubernamental Reporteros Sin Fronteras ${ }^{5}$; sin embargo, La Campaña Emblema de México -PEC, por sus siglas en inglés-, registró 11 asesinatos de periodistas en nuestro país en ese mismo año ${ }^{6}$, ubicándolo como el segundo país más peligroso del mundo para ejercer esta profesión; mientras que en primer lugar, se ubica a Filipinas, y seguido de México sitúan a Pakistán, Iraq, Siria, Somalia, Honduras, Brasil, Rusia e India.

Ya sea por la naturaleza de su trabajo o por los temas que abordan, el crimen organizado no respeta cargos, y tanto reporteros, fotógrafos, camarógrafos, editores y columnistas corren el riesgo de ser objeto de represalias. La violencia, la impunidad y la corrupción han cobrado la vida de más de 100 periodistas del año 2000 a la fecha. Según la organización Artículo 19, con sede en Londres, Inglaterra, en la última década se registraron 565 agresiones contra periodistas mexicanos. Tan sólo en 2011, la cifra fue de $172^{7}$ y de 137 de julio a octubre de 2012. . D el año 2002 al 2012, al menos 82 periodistas han sido asesinados ${ }^{9}$, sin distinciones en el cargo que desempeñan dentro de la empresa (reportero, editor, columnista, etc.).

Y peor aún, lejos de encontrarse una salida, la situación es cada vez más alarmante. Recientemente, la Felap declaró al 2011 como un "año fatal para el periodismo en México", toda vez que la suma total de asesinatos relacionados a la profesión fue de 17 en el país, entre 
ellos, 13 periodistas, dos trabajadores de prensa y dos familiares, además de dos desapariciones forzadas. Es decir, se habla de más de un homicidio cada mes ${ }^{10}$.

Carlos Moncada Ochoa, decano del periodismo en Sonora, precisa al respecto en su libro Oficio de muerte: "Hoy, México es uno de los países más peligrosos en el mundo para ejercer el periodismo, por la violencia ejercida por el crimen organizado contra los comunicadores. En el ranking de Reporteros sin Fronteras de 2012, el país se ubicó en el lugar 149, de 179 naciones. En Nicaragua, Venezuela, Ecuador, Bolivia, Panamá o Colombia hay mejores condiciones para informar en este continente, dice el organismo. Más de 50 mil muertos hasta finales de 2011 por la cruzada contra el narcotráfico del presidente Felipe Calderón, la muerte de 83 periodistas y la desaparición de otros 14 en una década componen un escenario de terror para informar"11.

El 2012 fue clasificado con adjetivos de sangriento y mortífero para los periodistas, pues la asociación Reporteros sin Fronteras asegura que a nivel mundial se incrementó en 33 por ciento el número de periodistas asesinados ${ }^{12}$. Mientras tanto, diversas organizaciones no gubernamentales defensoras de derechos humanos, de la libertad de expresión y de periodistas, coinciden al señalar que los estados de Veracruz, Chihuahua, Guerrero, Tamaulipas, Michoacán, Oaxaca, Estado de México, Nuevo León, Sinaloa y Sonora son donde se corre más riesgo en el ejercicio del periodismo ${ }^{13}$.

A nivel nacional el estado de Sinaloa se considera el más peligroso para los periodistas, sin embargo, los estados fronterizos del norte, como Sonora, también son de alto riesgo, y es aquí cuando la autocensura puede jugar un papel importante para salvar la vida de más de un periodista. La situación se vuelve cada vez más alarmante, y la sociedad pide a gritos que se detenga la ola de violencia generada en los últimos años, motivación principal de esta investigación.

Raúl Canseco Rojano, en Acercamientos a la libertad de expresión, establece que la agresión más alarmante en México es la provocada por la delincuencia organizada y el narcotráfico, particularmente por la impunidad que conlleva: "Aquí el periodista está inerme frente a sujetos que están fuera de la posibilidad de ser sujetos de la ley. Y aquí la preocupación cobra más fuerza porque estas agresiones están en proporción directa a la peligrosidad de las zonas, entre más alejada de la metrópoli, mayores las posibilidades de ser sujeto de una agresión, pues el periodista no solamente se encuentra su ejercicio profesional desamparado de un marco legal, sino que además padece de la presencia de autoridades ineptas, por lo decir menos, o de las autoridades que forman y participan de manera directa en las organizaciones criminales, ya sea porque participan de las grandes cantidades de dinero involucradas 0 porque están igualmente amenazadas e impotentes ante las organizaciones criminales" ${ }^{\prime 14}$.

En Sonora, el caso más recordado es el del joven Alfredo Jiménez Mota, quien desapareciera en abril de 2005 cuando trabajaba como reportero en El Imparcial, periódico de mayor 
circulación en el estado. Jiménez Mota realizaba investigaciones sobre el narcotráfico, y a 10 años de su desaparición, se desconoce su paradero.

Hace una década precisamente, el fallecido periodista Jesús Blancomelas, fundador del Semanario Zeta, quien sufrió un atentado del crimen organizado 2007, decía en su libro En estado de alerta:

"Los mafiosos han hecho de este país lo que quieren. Lo mismo imponen candidatos que compran gobiernos. Matan periodistas y ni quien les haga cosquillas. De eso no se ocupan los políticos. Me ha tocado por desgracia ver compañeros sangrantes. Agujereados por la espalda. Tiroteados por la cabeza.

No es posible que los periodistas siempre vayan adelante en las investigaciones de la mafia y los asesinatos de los compañeros. Atrasito la Procuraduría General de la República. Allí es donde están por montones los cómplices del narcotráfico. Ni siquiera tienen servicio de inteligencia. Nunca he visto un agente infiltrado. Jamás una operación en forma” ${ }^{15}$.

El 26 de enero de 2006, El Universal, periódico de circulación nacional, anunció la creación de "Proyecto Fénix", un equipo conformado por periodistas investigadores con la misión de profundizar en los trabajos que realizaban los reporteros asesinados o desaparecidos, y cuya primera tarea sería precisamente el caso de Alfredo Jiménez.

En el presente trabajo se analiza el caso de la desaparición del reportero José Alfredo Jiménez Mota, quien ha sido el único periodista desaparecido en la entidad; se realizan también entrevistas a profundidad, las cuales constituyen la parte esencial de este trabajo, y en las cuales participan periodistas que en su momento se vieron involucrados en situaciones de trabajo que pusieron en riesgo su vida, comparten la experiencia y las repercusiones que ésta ha tenido en su propia integridad.

Lo más preocupante es que de acuerdo a los integrantes de los medios consultados no existe una estrategia clara para la protección y capacitación de los reporteros en coberturas de alto riesgo. Se asume que hay hechos delictivos que no deben publicarse, y lo mínimo que salvaguarda al reportero es no firmar su nota o hacerlo con términos como "Redacción".

En este sentido Andrés Solís Álvarez, establece en su libro "Manual de autoprotección para periodistas" lo siguiente: "Trabajamos sin protección de nuestras empresas, sin seguro de vida, de gastos médicos, muchas veces sin gastos para traslados o alimentación, sin entrenamiento, porque pocas empresas de medios gastan en capacitación para sus periodistas y la mayoría terminamos pagando nuestros cursos a sabiendas que no obtendremos un mejor empleo y sólo podemos desequilibrar nuestra situación económica. No hay interés de los propietarios de los medios por la seguridad de su personal" ${ }^{16}$. 
Los reporteros advierten un estado de indefensión, y sobre el ámbito de las drogas solo se consideran en las publicaciones para las que trabajan, boletines de instancias gubernamentales y decomisos menores. De la misma forma, no se conoce entre los periodistas consultados reportajes o investigaciones especiales que se realicen localmente.

La autocensura "en medios informativos y entre periodistas de estados del país como Baja California, Sonora, Chihuahua, Coahuila, Tamaulipas, Michoacán, Guerrero y Oaxaca se ha hecho práctica generalizada tratándose de temas relacionados a la delincuencia organizada y su articulación con el poder público. Sin duda, es perniciosa para el ejercicio del derecho de libertad de expresión del medio y/ o del periodista que la toma, así como para su credibilidad, pero lo es ante todo para la colectividad a la cual se priva de información, afectándose con ello su derecho a estar informada" 17, apuntan Marco Lara y Francesc Barata en la publicación Nota roja.

Salvador de León Vázquez, investigador de la Universidad Autónoma de Aguascalientes, coincide que en el interior del país, "los periodistas se enfrentan a la percepción de salarios miserables, nulo apoyo de sus patrones, amenazas y agresiones de distintos actores sociales entre los que sobresalen los funcionarios públicos y la delincuencia organizada” ${ }^{18}$.

Raymundo Riva Palacio establece en La prensa de los jardines que la autocensura en más perversa que la censura, "puesto que mientras en esta última existe la posibilidad de rebelarse intelectualmente aunque se obedezca en la práctica, la autocensura es la claudicación de una mente independiente y la subordinación intelectual al poder".

"La autocensura es incuestionablemente el fenómeno predominante en México. Los gobiernos siempre han reconocido que para controlar al público, primero tienen que controlar la información, y los líderes de la democracia, no menos que los sabios, los shamanes, los reyes y los dictadores, son celosos del poder sobre las ideas y están tan hambrientos de controlar la información, como lo están por controlar los ejércitos" ${ }^{19}$.

La investigadora Balbina Flores Martínez abunda sobre la crítica situación latente en las salas de redacción mexicanas: "Las amenazas, agresiones físicas, el hostigamiento y los atentados a periodistas y medios siguen siendo una de las prácticas más comunes para amedrentar la libertad de expresión y el derecho a la información de periodistas y medios de comunicación. La autocensura se ha convertido en una consecuencia del temor y una forma de sobrevivencia. La censura en algunos medios, sobre todo televisivos y de radio, sigue siendo una práctica encubierta con los despidos laborales de periodistas indeseables o bien cancelación de programas, entrevistas y columnas" ${ }^{20}$.

Y bajo esta perspectiva, como en otros casos, no hay asociaciones periodísticas en Sonora que pugnen por mejores condiciones laborales y de seguridad. Las existentes, según estos 
profesionales de la comunicación, persiguen fines de grupo, intereses particulares que escapan al bien común de la colectividad. Existen entonces en Sonora, al igual que en otras entidades de México, silencio o indiferencia en este tipo de coberturas, lo que provoca una visión difusa o inexistente de esta realidad, con el consiguiente menoscabo a la libertad de expresión y el desarrollo a la sociedad.

Como enfatiza Perla Gómez Gallardo en su cuaderno de trabajo Libertad de Expresión, va en juego el derecho elemental del ciudadano a acceder a la información a través del trabajo periodístico:

"Sería absurdo e ilegal que el Estado afirmara que no censura más, que es una cuestión del crimen organizado y del narcotráfico, razón por la cual puede lavarse las manos. Pues no. El Estado es garante único de que la ley y la Constitución se cumplan (y por ende los derechos humanos que ella tutela), de no ser así carecería de sentido su existencia. Por supuesto, los periodistas que tratan temas de investigación y que ofrecen a la sociedad información que de otra manera no podría conocer son quienes sufren la mayor exposición a la descomposición del Estado de D erecho que vive el país. En este periodismo está, dicho sea de paso, el valor trascendente del derecho público a saber. De ahí que sea un asunto de interés público" ${ }^{21}$.

La misma autora en el libro Compromiso con la libertad de expresión, sugiere que "los Estados deben implementar medidas, que van desde la actualización de leyes (sin convertirlas en limitantes) y otorgamiento de facultades a las autoridades que las optimicen, y generen los instrumentos legales que permitan el eficaz castigo para los que atenten contra el ejercicio de la libertad de expresión, así como los mecanismos que incentiven el ejercicio responsable del mismo" 22 .

Frida Viridiana Rodelo, en el artículo Periodismo en entornos violentos: el caso de los periodistas de Culiacán, Sinaloa, entidad que colinda con Sonora, alerta sobre aquellas agresiones que están al margen de los registros que llevan las asociaciones de protección a periodistas, "en las que los límites de la libertad de prensa se manifiestan de forma más sutil, como es el caso de la autocensura y la disminución del periodismo crítico y de denuncia ocasionadas por temor a represalias, respeto excesivo a la autoridad y presiones institucionales. La libertad de prensa - en su sentido colectivo- también puede ser limitada a consecuencia de la falta de interés social por parte de los medios informativos o periodistas" $^{23}$.

En el Informe Buendía, un análisis hemerográfico sobre los obstáculos a la libertad de expresión en México, se plantea el reto del trabajo reporteril ante la intromisión de diversos agentes que frenan su desarrollo: "La situación del ejercicio periodístico en México es francamente desoladora. Hasta hace pocos años, los agresores o aparentes responsables de vulnerar las libertades de información y expresión más recurrentes eran gente del Poder Público en todas sus variantes. Ahora, sin embargo, se añaden otros actores igualmente 
graves: desde grupos sociales hasta el crimen organizado, pasando por los intereses económicos y políticos de los mismos propietarios mediáticos" ${ }^{24}$.

Frente al clima de acoso, censura y represión periodística, en el documento se subraya que la respuesta de legisladores y funcionarios de distintos niveles es de nulos resultados reales, donde "reina la impunidad ante la ineficacia e inoperancia de las autoridades".

Es en este escenario donde el reportero debe a contracorriente desempeñar una profesión que lo somete a una prueba constante de sobrevivencia e, incluso, creatividad para contar la realidad, como lo comparte Silvia González Quintero:

"D ocumentar la tragedia, no es fácil. La apología de la violencia se condena pero ante tanta barbarie el periodismo se encuentra en el dilema de cómo documentar la terca realidad: denunciar las violaciones, los abusos del poder formal pero también del narco que estimula la autocensura pero también las otras historias. Por eso el periodismo mexicano tiene el enorme desafío de no alentar la desesperanza. D ar cuenta de las acciones de miles de ciudadanos que a pesar de los horrores ponen en práctica su creatividad y valor para sobrevivir" ${ }^{25}$.

\section{Metodología}

El presente proyecto de investigación es meramente de corte cualitativo, aunque para poder contextualizar y dimensionar el crimen organizado que se vive en Sonora, y su relación con el periodismo, fue necesario recurrir a algunos datos estadísticos, arrojados por instancias certificadas.

A partir de conocer la situación que se vive en el noroeste del país, fue preciso identificar un grupo de periodistas de tres municipios clave en el estado de Sonora para dar sustento al proceso de investigación, a quienes se les aplicó entrevistas a profundidad y otros participaron en grupos focales.

Se trabajó estratégicamente con periodistas de Nogales, como ciudad fronteriza; en Hermosillo, como capital y municipio más poblado, y en Ciudad O bregón, la más importante en el sur del estado, con el objetivo de conocer la percepción sobre la problemática y, por qué no, la propia experiencia del periodista con el crimen organizado en el ejercicio de su profesión.

Se utilizó también la metodología de grupos focales, los cuales sirvieron para el intercambio de ideas de quienes podrían encontrarse más expuestos ante cualquier escenario delictivo, en cambio, algunas salas de redacción fueron el sitio indicado para la aplicación de cuestionarios, de esta manera se obtuvo la impresión del periodista que cubre otro tipo de fuentes, pero que no por ello deja de preocuparle lo que sucede en su quehacer diario. 
En total, fueron consultados 27 periodistas de las tres ciudades mencionadas, entre reporteros, editores y directivos de periódicos, estaciones de radio, canales de televisión y portales informativos.

A continuación se adjunta tabla con información de los comunicadores que accedieron a participar en este proyecto en la modalidad de entrevistas de profundidad.

Hermosillo

\begin{tabular}{|c|c|c|c|}
\hline Nombre & Actividad & Empresa & Fecha \\
\hline Luis Alberto Medina & Director & Proyecto Puente & $\begin{array}{l}5 \text { de septiembre de } \\
2011\end{array}$ \\
\hline $\begin{array}{ll}\text { Conrado } & \text { Quezada } \\
\text { Rodríguez } & \end{array}$ & Director de noticias & Tv Azteca Sonora & $\begin{array}{l}10 \text { de octubre de } \\
2011\end{array}$ \\
\hline Marco Antonio Piña & Reportero & Televisa Hermosillo & $\begin{array}{l}25 \text { de octubre de } \\
2011\end{array}$ \\
\hline Ramsés Tamayo & Reportero & El Imparcial & $\begin{array}{l}26 \text { de octubre de } \\
2011\end{array}$ \\
\hline $\begin{array}{l}\text { Gustavo Alfonso } \\
\text { Dueñas Molina }\end{array}$ & Reportero & Freelance & $\begin{array}{l}24 \text { de septiembre de } \\
2011\end{array}$ \\
\hline Diego Pinto & Reportero & Expreso & $\begin{array}{l}11 \text { de octubre de } \\
2011\end{array}$ \\
\hline $\begin{array}{ll}\text { Alfonso } & \text { Campos } \\
\text { Rubio } & \end{array}$ & Reportero & Freelance & $\begin{array}{l}15 \text { de octubre de } \\
2011\end{array}$ \\
\hline Julián O rtega & Reportero gráfico & El Imparcial & $\begin{array}{l}22 \text { de octubre de } \\
2011\end{array}$ \\
\hline Priscila Cárdenas & Reportera & Expreso & $\begin{array}{l}10 \text { de septiembre de } \\
2011\end{array}$ \\
\hline $\begin{array}{ll}\text { Martín } & \text { Vallejo } \\
\text { González } & \end{array}$ & Reportero & Freelance & $\begin{array}{l}11 \text { de noviembre de } \\
2012\end{array}$ \\
\hline $\begin{array}{ll}\text { Carlos } & \text { Moncada } \\
\text { Ochoa } & \end{array}$ & Reportero y escritor & Freelance & $\begin{array}{l}22 \text { de noviembre de } \\
2012\end{array}$ \\
\hline $\begin{array}{l}\text { Ana Luisa Pacheco } \\
\text { Gracia }\end{array}$ & $\begin{array}{l}\text { Reportera } \\
\text { conductora }\end{array}$ & La Jornada & $\begin{array}{l}24 \text { de noviembre de } \\
2012\end{array}$ \\
\hline
\end{tabular}


Nogales

\begin{tabular}{|l|l|l|l|}
\hline Nombre & Actividad & Empresa & Fecha \\
\hline Rubén Ruiz & Reportero & El Imparcial & $\begin{array}{l}10 \text { de octubre de } \\
2011\end{array}$ \\
\hline César Barragán & Reportero & El Diario de Sonora & $\begin{array}{l}1 \text { de octubre de } \\
2011\end{array}$ \\
\hline Raúl H. Leyva & Reportero & Radio Xeny & $\begin{array}{l}2 \text { de octubre de } \\
2011\end{array}$ \\
\hline $\begin{array}{l}\text { Hiram González } \\
\text { Machi }\end{array}$ & $\begin{array}{l}\text { Reportero } \\
\text { conductor }\end{array}$ & $\begin{array}{l}\text { Nuevo Día de octubre de } \\
\text { Canal 7 }\end{array}$ \\
\hline Sergio García & Corresponsal & Radio Sonora & $\begin{array}{l}10 \text { de octubre de } \\
2011\end{array}$ \\
\hline
\end{tabular}

Cajeme

\begin{tabular}{|l|l|l|l|}
\hline Nombre & Actividad & Empresa & Fecha \\
\hline Ramsés Tamayo & Director editorial & El Valle & $\begin{array}{l}24 \text { de septiembre de } \\
2011\end{array}$ \\
\hline David Morgán & Director de noticias & $\begin{array}{l}\text { Tv Azteca Sonora } \\
\text { Sur }\end{array}$ & 7 de febrero de 2012 \\
\hline $\begin{array}{l}\text { Gustavo Alfonso } \\
\text { Dueñas Molina }\end{array}$ & Reportero & Freelance & 8 de febrero de 2012 \\
\hline $\begin{array}{l}\text { Alfonso Pliego } \\
\text { Walldez }\end{array}$ & Reportero & $\begin{array}{l}\text { Portal } \\
\text { Palabra }\end{array}$ & 7 de febrero de 2012 \\
\hline Michel Inzunza & Reportero & Freelance & $\begin{array}{l}25 \text { de septiembre de } \\
2011\end{array}$ \\
\hline Yajaira Bracamontes & Reportero & Freelance & $\begin{array}{l}24 \text { de septiembre de } \\
2011\end{array}$ \\
\hline Martín Mendoza & Reportero & Diario del Yaqui & $\begin{array}{l}5 \text { de noviembre de } \\
2011\end{array}$ \\
\hline
\end{tabular}

Para la realización de las entrevistas de profundidad se aplicó el siguiente modelo de preguntas a los comunicadores, quienes previamente proporcionaron su nombre completo, medio de comunicación en el que se desempeñaban laboralmente y una breve reseña curricular.

¿Cómo se realiza la cobertura informativa de la fuente policiaca? 
¿Existen temas relacionados con el narcotráfico que por su propia naturaleza no se cubren ni se publican?

En caso de que la respuesta sea afirmativa, proporcionar algún ejemplo.

¿Existe capacitación para el reportero sobre cómo atender esta fuente informativa y qué hacer en situaciones de riesgo?

¿Cuáles son los mecanismos de protección para el reportero de la fuente policiaca cuando es agredido?

¿Hay alguna limitante en la cobertura informativa de eventos policiacos?

¿Identifica alguna asociación de periodistas que brinden apoyo o protección en caso necesario?

¿Cuál es el comportamiento del gremio periodístico ante los ataques o agresiones a otros colegas?

¿Considera que existe unió en el gremio periodístico ante situaciones de ataque o agresiones a otros periodistas?

¿Hay alguna limitante en la cobertura de temas policiacos?

¿Qué hacer ante el panorama de que México está entre los países considerados más peligrosos para ejercer el periodismo?

En el caso de los participantes del grupo focal realizado el 17 de septiembre de 2011, estuvieron los siguientes reporteros y se aplicó el mismo modelo de preguntas anteriormente expuesto:

\begin{tabular}{|l|l|l|}
\hline Nombre & Actividad & Empresa \\
\hline $\begin{array}{l}\text { Guillermo González } \\
\text { Vera }\end{array}$ & Reportero & Expreso \\
\hline Olivia Santana & Reportero y conductora & Radio SA \\
\hline Eleazar Escobar & Reportero gráfico & Expreso \\
\hline Luis Arvayo & Reportero & El Imparcial \\
\hline
\end{tabular}

Los resultados de la investigación son los que se describen a continuación.

\section{Resultados}

Citando el caso particular de Sonora, el caso más representativo es el del ya mencionado reportero Alfredo Jiménez Mota, quien desapareció en 2005 cuando trabajaba para el diario de mayor circulación El Imparcial, sin que hasta el momento las investigaciones hayan arrojado noticias sobre el paradero del entonces joven de 25 años de edad; y sobre el tema, los periodistas entrevistados arrojan la siguiente información: 
Entre quienes conocieron a Jiménez Mota se encuentra el periodista Luis Alberto Medina, actualmente director de Proyecto Puente, y quien lo describe como un reportero "valiente y muy apasionado por su trabajo, amaba y creía en el oficio". Rubén Ruiz, corresponsal de El Imparcial en Nogales por su parte, considera que "era muy celoso de sus fuentes, se cegaba con ellas y se reservaba la identidad". Ramsés Tamayo ex compañero de trabajo y actual director editorial del periódico El Valle, está convencido de que "fue un descuido suyo no informar lo que estaba haciendo, y se expuso demasiado". Mientras que Alfonso Campos Rubio, reportero independiente, responsabiliza al gobierno y al que incluso acusa de estar vinculado con el crimen organizado: "Alfredo investigaba nexos de funcionarios gubernamentales con el narco, y andaba por una buena pista, desgraciadamente el enemigo está en casa y a él lo vendieron", señala.

De esta manera algunos de los periodistas consultados para esta investigación encuentran como principal responsable al medio para el que el reportero trabajaba, mientras que otros culpan al gobierno, y más de uno opina que el mismo Alfredo no tomó las precauciones que debía. Lo cierto es que este hecho marca un "parteaguas", un antes y un después en el periodismo de investigación en el estado y en la cobertura informativa relacionada con temas propios de la fuente policiaca, coinciden los entrevistados.

“Se marcó una línea muy fuerte en la cobertura policiaca con su desaparición. Fue como lo decisivo para que nosotros entendiéramos que no hay nadie que nos defienda, que por más valiente que sea, el reportero está expuesto", opina Olivia Santana, ex conductora de Radio SA y actualmente conductora de Telemax. Por su parte, Priscila Cárdenas reportera del periódico Expreso, piensa que el periodismo policiaco se limitó y se frenó a raíz de este hecho. "Se rebajó, ahora ponen a quién mataron y cómo, pero la investigación desapareció completamente".

El 30 de agosto de 2005, en el Encuentro de Editores Fronterizos, un total de 20 directivos de medios de comunicación y cuatro representantes de la Sociedad Interamericana de Prensa (SIP), firmaron la "Declaración de Hermosillo", que consistía en cinco acciones para defender el trabajo de los periodistas. Uno de los compromisos fue brindar capacitación para las coberturas de alto riesgo. Otro, conformar un equipo de periodistas, con la misión de profundizar en los trabajos que realizaban los compañeros del gremio antes de ser asesinados o desaparecidos, además de investigar qué había sucedido con esos colegas.

Así, el 26 de enero de 2006, a 300 días de la desaparición de Alfredo Jiménez, se anunció la creación de "Proyecto Fénix", cuya primera tarea sería precisamente el caso del reportero de El Imparcial. El citado acuerdo fue firmado en la ciudad de Nuevo Laredo, Tamaulipas, por representantes de 40 medios de comunicación, con el respaldo de la SIP. ${ }^{26}$ El 2 de abril de ese año, se publicó en varios periódicos del país el primer reporte de Proyecto Fénix. 
Para Luis Alberto Medina, director de Proyecto Puente, fue un intento al que no se le dio seguimiento y considera un antes y un después a partir de que como colegas se remitieron sólo a la información oficial que se proporcionó del caso. Reconoció la unión del gremio periodístico a través de marchas para exigir el esclarecimiento del caso, pero con el paso del tiempo el gremio claudicó en su reclamo de justica, lo cual es atribuible también a que la empresa El Imparcial se limita sólo a entrevistar a los padres de Jiménez Mota cada aniversario de su desaparición y lleva un conteo, considerado por el mismo Luis Alberto Medina, como frívolo pero no es un medio de comunicación que presione a las autoridades ni que cuente con política editorial para hacerlo, advirtió.

\subsection{La fuente policiaca}

La forma de laborar de los reporteros de la fuente policiaca es común en la mayoría de ellos: recurren al escáner o radio, el cual cuenta con la frecuencia de la policía municipal, también visitan diariamente las instalaciones de la comandancia, en busca de los partes informativos, que contienen los datos de los sucesos a los que acuden los policías y a partir de ahí deciden si alguno de los hechos reportados tiene potencial para ser noticia.

Otra fuente de información, dicen los entrevistados, son los "contactos" que el reportero hace en su trabajo diario. Los mismos oficiales, o a veces los vecinos o testigos, cuando tienen la manera de avisar al reportero de algún hecho lo hacen. Y además, se suma otro elemento para dar aviso cuando algo importante ocurre: las redes sociales, quizá no como el método más confiable, pero sí muy utilizado.

Los reporteros pueden trabajar en prensa escrita, radio, televisión o portales de internet, pero el género periodístico por excelencia en este tipo de coberturas es el mismo: la nota informativa, conocida en la fuente como la nota roja ${ }^{27}$, y que va desde un accidente, un homicidio o un suicidio, sólo por citar algunos casos; sin embargo, hay periodistas que consideran que el valor agregado a cubrir la fuente policiaca reside en la obligación que el reportero tiene de consultar varias fuentes antes de publicar su nota.

"Ninguna fuente te enseña a reportear; te enseñan a hacer entrevistas, y aparte funcionas con la grabadora y dependes de lo que te diga otra persona, y en la policiaca no, necesitas saber consultar documentos, fuentes, confirmar datos. En realidad la fuente policiaca es la que te da el sustento para poder crecer, si no trabajas bien como reportero para obtener información, nunca vas a destacar como reportero", explica Conrado Quezada Rodríguez.

Julián O rtega, reportero gráfico de El Imparcial, señala que el periodismo de investigación en Sonora se hace muy poco y eso debe a los riesgos que implica, no hay libertad para hacerlo pero reconoció la importancia de éste. En el caso de Marco Antonio Piña, reportero de 
Televisa Hermosillo, argumentó que la razón principal de lo anterior es la necesidad inmediatez en la cobertura y publicación de la información, y ello no da tiempo de hacer reportajes, porque los noticieros son del día.

Mientras tanto César Barragán considera que el avance que se desea tener en una investigación depende más del propio periodista que del medio de comunicación para el cual labora, aunque puntualizó que en el ámbito policiaco no se puede investigar mucho, porque se tocan intereses "y cuando quieres llegar a la persona, ya se enteró, o ya te mandó decir que no lo hagas".

Una medida de seguridad en la que casi todos los periodistas entrevistados coinciden, es en dejar de buscar la exclusiva al acudir al lugar de los hechos, según hizo saber Eleazar Escobar, reportero gráfico de Expreso, toda vez que conseguir un primicia en estas condiciones, no vale el riesgo de ponerse en peligro. Mencionó que llegar a tiempo a un evento relacionado con hechos del narcotráfico, es un error: "yo entendí que tenía que ser más inteligente, y sin que eso me quitara mí profesionalismo y mis ganas de trabajar. Opté por llegar, estar cerca y quedarme a dos cuadras hasta que escuchara algo, y que los policías no me vieran", reconoció.

Para Sergio García, corresponsal en Nogales para Radio Sonora existen cambios en las costumbres de los periodistas, pues con la peligrosidad del narcotráfico y la desaparición de Alfredo Jiménez Mota, hay que procurar trabajar en grupo y renunciar la nota exclusiva por cuestiones de seguridad. "Por ejemplo si matan a tres personas, y llega primero un periodista, nos hablamos entre los compañeros, 'oye, ando aquí, échame la mano para no llegar solo',

Rubén Ruiz, de El Imparcial en Nogales, hizo hincapié en la importancia de procurar una apariencia adecuada y vestimenta apropiada para desempeñarse como reportero, pues señaló que hay periodistas que parecen policías. Destacó que otra medida de seguridad que él emplea es dejar su automóvil estacionado en un lugar seguro y lo más cercano posible, además de portar a la vista la identificación de la empresa donde trabaja.

Para Marco Antonio Piña, decano en la cobertura de la fuente policiaca en Hermosillo y reportero de Televisa Hermosillo, la desaparición de Alfredo Jiménez marcó un antes y un después en las medidas de seguridad de los periodistas y lo relacionado a la cobertura periodística. Una forma de evitar problemas al momento de recabar información relacionada con hechos delictivos es evitar la investigación; en relación a la seguridad de las empresa, indicó que éstas han adoptado diversas medidas y en el caso de Televisa Hermosillo piden a sus reporteros que siempre porten la identificación correspondiente y que al salir de las instalaciones no se queden por afuera de las mismas, a fin de evitar ser víctimas de bombas o balazos. Reconoce que no siempre fue así, pues antes las agresiones sólo llegaban a los golpes y hoy en día son amenazas de muerte que en ocasiones se cumplen, situación que califica como un "cambio de reglas". 


\subsection{Censura y autocensura}

Coartar la libertad de expresión del periodista es un fenómeno que encierra muy diversos abordajes para su análisis, situaciones donde cada medio de comunicación es puesto a prueba, no solo en cuanto al compromiso moral y ético con la sociedad, sino a la propia sobrevivencia personal y familiar de su cuerpo de reporteros, particularmente en coberturas de alto riesgo.

El jefe de información tiene la responsabilidad de guiar a su cuerpo de reporteros, avisarle cuando está lastimando intereses, lo cual no consideró un acto de censura, sino de protección, explicó David Morgan, director de Noticias de TV Azteca Sonora Sur, con sede en Ciudad O bregón, municipio de Cajeme, localidad en la que se registraron 100 ejecuciones violentas en el 2012. Una alternativa ante esta situación, agregó, es analizar la información que el reportero ha recabado y determinar el abordaje periodístico que se le brindará.

Aseveró que es imposible exigirle al reportero que se meta en problemas al publicar cierta información sólo pensando en el interés del medio de comunicación. En México, el periodismo es considerada una profesión de alto riesgo, pero desgraciadamente el sueldo que pagan los medios al periodista no corresponde a los riesgo que enfrenta, indicó el experimentado comunicador con más 30 años de trayectoria.

Cada uno de los más de 20 reporteros consultados para esta investigación acusaron actos de censura, además de reconocer que se ven obligados a autocensurarse, pues ante la falta de garantías es preferible no publicar o difundir determinados hechos delictivos o personajes involucrados en ellos.

\subsubsection{Variantes de la censura}

Según los entrevistados, la censura se manifiesta principalmente en dos variantes: una es el momento en que las autoridades y corporaciones policiacas establecen restricciones para que el comunicador acceda a la información que van desde abusos, agresiones e intimidaciones por parte de los agentes del orden; así como el inminente peligro que representa la comupción y la colusión de los representantes de la ley con el crimen organizado.

César Barragán, reportero de El Diario de Sonora en Nogales, indicó que diariamente las autoridades buscan la manera de ocultar información, dejando de manifiesto su interés por proteger la identidad del detenido, por no dar a conocer la manera en que se dieron los hechos, 0 , si hay nivel de violencia, son datos que siempre se ocultan; cuestión que atribuyó a intereses del mismo gobiemo. Reveló que él mismo ha sido víctima de agresiones en muchas ocasiones, desde incidentes en que le arrebatan la cámara fotográfica, empujones o le tapan la 
visibilidad para impedir capte algún registro fotográfico, en acciones que protagonizan tanto agentes policiacos del nivel municipal, estatal y federal.

Este tipo de condiciones al ejercer la profesión en el lugar de los hechos son frecuentes, los periodistas son objeto de actitudes despóticas y amenazas por parte de la policía, a pesar de que se sujeten a criterios que obstaculizan su labor, como el que las autoridades ministeriales ordenen acordonar el área del delito en un perímetro de hasta 300 metros.

Al respecto César Barragán compartió que en algunas ocasiones ha sido víctima de agresiones que van desde los insultos verbales cuando se acerca a la escena del crimen y los agentes policiacos espetan frases como: 'hey, ya llegó el mitotero', 'cierren, hagan vallas', 'jálalo para allá, no lo dejes entrar'. Pero cuando el reportero acude sin compañía de otros colegas a cubrir la información, es más factible que los agentes policiacos agredan principalmente si son ejército y federales, quienes llegan incluso a encañonar con sus armas al reportero o someterlos físicamente.

En enero de 2012 en Ciudad Obregón, ubicada a 252 kilómetros al sur de la capital de Hermosillo, se presentó un ataque por parte de agentes de la Policía Estatal Investigadora en contra del reportero Alfonso Pliego, quien labora para el portal Última Palabra. A pesar de la presencia de representantes de los medios de comunicación, y que incluso los oficiales fueron consignados en video, el sometimiento fue permanente: el periodista fue esposado, llevado a una patrulla, empujado y amenazado para que soltara una cámara de video. Hasta los reporteros que intentaron defenderlo fueron ofendidos por policías encapuchados. La razón: invadir la escena del crimen.

Alfonso Campos Rubio, considerado un veterano en la crónica de la nota roja, descalifica la forma en que se conduce la autoridad ante estas situaciones pues a los reporteros se les mantiene retirados de la escena del crimen de 200 a 300 metros, lo que provoca la especulación de que el gobiemo algo esconde; sin embargo, sí pueden acercarse al lugar los vecinos o vendedores ambulantes, y el protocolo establece que el periodista puede encontrarse en un mínimo de 50 metros a la redonda.

A finales de febrero de 2011, Julián O rtega, reportero gráfico de El Imparcial, sufrió un ataque físico y verbal por parte de miembros de la Policía Estatal Investigadora cuando cubría la muerte de dos agentes de esta corporación al enfrentarse a sicarios en Hermosillo. El profesional de la lente recuerda que se encontraba en el sitio donde se desarrollaba un operativo a cargo de agentes policiacos, quienes revisaban cada una las viviendas del lugar, aparentemente sin orden de cateo, mientras él tomaba fotos. Cuando los elementos de seguridad se percataron de su presencia se retiraron del lugar y se acercaron a Julián O rtega, mientras éste se retiraba del lugar al tiempo que pedía a los agentes le permitieran hacer su trabajo. Sin una línea divisoria que estableciera un límite que no debía ser rebasado, los agentes policiacos trataron de quitarle a O rtega su cámara fotográfica, lo cual lograron por un 
instante, además de amenazarlo y sujetarlo por el cuello, lo cual le provocó lesiones. Cuando los representantes de la justicia se dieron cuenta que laboraba en un medio de comunicación lo dejaron ir y le regresaron su herramienta de trabajo. Este acontecimiento trascendió mucho en redes sociales y causó revuelo, de tal manera que periodistas de la Ciudad de México, Derechos Humanos y asociaciones de periodistas, expresaron su indignación por el trato que tienen las autoridades de Sonora hacia los periodistas.

Comunicadores de la vieja guardia, como Martín Mendoza del Diario del Yaqui de Ciudad Obregón, advierte que ante esta situación se emplaza al periodista a comunicados oficiales, con la visión que las corporaciones desean presentar y eso no debe ser así, ya que se debe indagar aquella información que no está a la vista y que los comandos policiacos tratan de minimizar o guardar bajo el argumento de que no pasa nada.

Sobre el tema, Alfonso Campos Rubio reconoce que no es sencillo y cada vez resulta más complejo investigar, y es que anteriormente había más libertad de profundizar en los asuntos que manejaban los cuerpos policiacos e incluso era fácil tener acceso a documentos oficiales de investigación para hacer la nota; ahora, no permiten ni la consulta de éstos. Por otra parte, las restricciones para acceder a la información también se establecen cuando se solicitan entrevistas con funcionarios públicos de primer nivel, para intentar profundizar en los hechos; a pesar de que su obligación es rendir cuentas ante la sociedad, se imponen trabas para que estos servidores lo hagan a través de los medios de comunicación.

Conrado Quezada considera que a las autoridades policiacas no les interesa informar, lo cual, aunado a la ya difícil tarea de informar, se convierte en un reto mayúsculo; pero, cuando se tiene la sospecha de que la misma autoridad está coludida con el crimen organizado, aunque sea presunción o una realidad, entonces el temor es latente.

Ante la incertidumbre de no saber qué intereses se lastimarán es mejor evitar hacer comentarios, situación ante la que Martín Mendoza hace un llamado de atención: "No te puedes meter con cualquier tipo de gente porque se nos puede ir la vida. El enemigo puede ser un enemigo oculto y sin darte cuenta puedes ser cazado. Es muy importante la malicia y la prudencia, ya que muchas veces caemos en el libertinaje".

Para Alfonso Campos Rubio, el adversario principal en esta clase de coberturas es el mismo grupo en el poder sin importar el nivel social, económico, político o partidista, pues considera que la gran mayoría de los asesinatos y desapariciones de periodistas han sido a manos del gobierno, no tanto del crimen organizado.

“Con respecto a la cobertura de la información peligrosa, a mí me han levantado dos veces, y no soy muy agresivo que digamos, yo mantengo cierto límite, precisamente para la cuestión de protegerme a mí y a mi familia; sin embargo, en estos últimos 10 años, dos veces me han 
levantado y me han puesto unas chingas de padre y señor mío, que me han dejado medio muerto, precisamente por cuestiones de comentarios y de publicación, eso no tiene duda", recuerda Raúl Leyva, conductor radiofónico y director del periódico Tercer Milenio de Nogales.

Además del ataque físico, varios de los periodistas consultados comentan haber recibido llamadas telefónicas o correos electrónicos intimidatorios, automóviles sospechosos que los siguen, y actos de advertencia como la cabeza de un animal muerto o un moño negro, colocados por fuera de su centro de trabajo. El mensaje directo o indirecto es recibido, queda claro que es por ir más allá de lo que el crimen organizado ve con buenos ojos.

Es una situación de descomposición social, donde la autoridad ha sido rebasada, dice Martín Mendoza: "Ha habido mucho libertinaje de parte de autoridades hacia la delincuencia, ellos definitivamente han tomado una potestad que está por encima de los gobernantes. Quienes dirigen los destinos de municipios pueden decir que no es cierto para ellos, pero estamos viendo cómo los delincuentes hacen y deshacen. Se ha perdido el respeto hacia las instituciones encargadas de velar la salvaguarda y tranquilidad de la familia, y sí hay situaciones que uno como periodista se limita, porque el arma de uno es el raciocino, la razón y la pluma para ejercer el periodismo. En cambio, para los delincuentes eso sale sobrando, vienen y te acallan o te amenazan, y enfrentamos el riesgo que se metan con tu familia, nos pegan donde más nos duele".

Con toda impunidad, en Ciudad O bregón se han presentado casos donde se refleja la manera de proceder de las bandas delincuenciales. Son capaces de recorrer cada medio de comunicación para encontrar al autor del material periodístico. David Morgan lo platica de esta manera: "Se dio el caso que alguien sacó una nota en la radio, y de repente un comando andaba en una camioneta Expedition, eran varias personas encapuchadas y llegaron directamente a las estaciones: 'Eit, quién dio esa información... ', 'No, espérate, espérate, ni noticiero tenemos...', 'Ah, bueno, gracias'. Hasta eso que dicen que muy educados y se retimaban y a todas las radios fueron; afortunadamente a la última que fueron, de ahí había salido la información. Francisco Pérez Díaz les dijo: 'Yo saqué la información -era sobre un levantado-, pero la información la saqué del periódico, ahí está el periódico', y se los enseñó. Se fueron al Diario del Yaqui, porque de ahí había salido esa información, pero para cuando llegaron, las autoridades ya habían dado el pitazo a todos los periodistas, y a ese reportero ya lo tenían resguardado".

Cuando la amenaza es seria, el reportero debe velar por su propia integridad, como le sucedió a Martín Vallejo.

"He recibido amenazas, inclusive tuve que salir del país por aproximadamente mes y medio, empecé a recibir amenazas por internet y cosas que vi alrededor de mi casa, movimientos muy extraños, entonces dije 'aquí hay algo'. Fue por el caso de una señora que levantaron, 
esposa de un conocido narcotraficante, y manejamos datos, fotografías, quiero pensar que de ahí vino todo".

Las redes de la delincuencia también tocan al gremio periodístico. Se sabe de reporteros que tienen fuertes nexos con el narcotráfico, o de entomos de trabajo donde no se goza de cabal libertad porque hay espías del crimen organizado.

"Por lo general, en cada ciudad hay un representante de los narcos entre los periodistas, o es en enlace entre los narcos, y él les dice a los demás periodistas: 'Oye, sabes qué, dicen allá que esa nota mejor ni la saques... o sabes qué, esa nota dicen que sí porque es un mensaje que traen estos contra los otros'. Eso lo sabemos porque nos lo platican los mismos periodistas, la gente de las fuentes", enfatiza David Morgan.

\subsubsection{La autocensura. Difundir solo lo necesario, aun contando con la información disponible}

“¿Por qué no se hacen reportajes cuando tenemos capos de la mafia aquí? No se hacen ¿por qué? Porque tenemos miedo, y no tenemos miedo precisamente si esa persona nos concede entrevista, a la mejor sí la podemos sacar y todo, y se va a vender bonito el periódico; a lo que le tenemos miedo es que el grupo contrario venga y te levante y te diga: '¿D ónde hiciste la entrevista?, ¿cómo es?, ¿tienes una foto actualizada?, ¿qué carros trae?, ¿cuánta gente tiene?, ¿qué armamento tiene?’. Aquí se sabe dónde se reúnen, todo mundo lo conoce”, señala Alfonso Pliego, sobre la imposibilidad de cubrir a los actores vinculados al trasiego de droga.

Hay una frontera muy delimitada para la prensa que cubre la fuente policiaca en Sonora, en temas de alto riesgo: apegarse a la versión oficial de los hechos que ofrece la autoridad a partir de declaraciones o boletines, o bien, realizar el trabajo periodístico cumpliendo los criterios mínimos de una nota informativa, o incluso menos que eso: se está alerta de los nombres, de las propiedades que se mencionan, de cualquier dato que pueda molestar a intereses oscuros del narco o de la delincuencia organizada.

Esas precauciones son reglas no escritas en las salas de redacción: "Mencionar un carro, una casa, un negocio, que sabemos que tiene relación con esa persona, o que es pariente 0 amigo de esa persona, es echarte la soga al cuello tú mismo", expresa Alfonso Pliego.

"Voy a ser honesto, hemos decidido, ya después que se ventila de qué personaje se trata, no mencionar el apodo, porque muchas veces el apodo es más fuerte que incluso el nombre de pila”, menciona César Barragán, periodista de Nogales. 
“(En el medio) te dicen 'es que ese tipo trabajaba para fulanito de tal', no vas a poner el nombre de fulanito de tal, aunque tú sepas que es el que mueve la droga, por ejemplo, 'es que trabajaba para el Chapo Guzmán', no lo vas a poner porque... uno: no te consta, dos: puede ser algo riesgoso", subraya Priscila Cárdenas, reportera de Hermosillo, especialista en la fuente policiaca.

Olivia Santana, conductora y periodista radiofónica, puntualiza en aquello que se deja de publicar y los motivos para hacerlo:"Está muy fácil, el narcotráfico. Estás en esa disyuntiva: 'yo voy a decir de los Beltrán Leyva, y voy a decir del '2000' (Francisco Hemández García) que se reúne con los mismos policías en una casa acá, y voy a decir del Chapo Guzmán que se pasea por la casa de no sé quién y que... ', pero ¿a mí quién me va a proteger? Y no siento la confianza ni nunca la voy a tener en las instituciones, porque están igual de metidas en el lodo, absolutamente todas. Eres un ente que no tienes nadie que te defienda, ni una empresa, no tienes asesoría legal. Si vas y platicas con gente de la (policía) federal, ellos ni siquiera quieren decir el nombre del Chapo Guzmán, ellos que tienen un búnker con toda esa seguridad, qué te dejan a ti, que tú no traes una pistola, que no tienes un tanque blindado".

Por tanto, el tratamiento informativo es únicamente con los datos elementales, con lo sucedido en el aquí y el ahora. Ya ni hablar de un seguimiento informativo de cada uno de los casos, como lo comparte Hiram González:

"Surgen muchas limitaciones por los miedos que les infunden a algunos periodistas, dicen que el que sabe menos vive más, entonces es difícil escarbar en donde con lo que te vas a topar puede ser peligroso para tu propia vida. Lo que hacemos aquí en Nogales, en muchas ocasiones, es cubrir únicamente la información, dar a conocer el hecho: una persona murió, de tal forma, en tal parte, y tratar de evitar quién fue, cómo, por qué, o qué relación tenía esa persona con alguien. Ahí es donde sí entra la autocensura”.

Lo irónico de esta situación es que, cuando es posible conocer ciertos detalles ligados al crimen organizado, se desconfía, no se desean publicar, se piensa en la posibilidad de ser utilizado como vocero del narco, como lo expresa David Morgan:

"Tu primer instinto como periodista es desconfiar de todo y de todos, inclusive... 'qué traes atrás, porque me estás soltando (la información) así de facilito, algo tienes, algo quieres y me quieres usar', es lo primero que te tiene que brincar como periodista, los focos rojos cuando alguien te está soltando la información".

Una prueba para la prensa local fue la captura de cuatro integrantes de los Zetas en Ciudad Obregón, por parte del Ejército Mexicano, a principios del mes de febrero de 2012. Los medios fueron convocados a la cobertura, se tuvo acceso a la casa de seguridad, se pudo 
fotografiar a los detenidos, se contaba con sus nombres. Cada medio decidió qué difundir, no todos se atrevieron a hacerlo con lujo de detalles. Así lo menciona Alfonso Pliego:

“¿Para qué manejar nombres, qué caso tiene? Que los dé a conocer la Procuraduría, la Secretaría de la D efensa Nacional o la Policía Estatal Investigadora. Pero uno ipor qué? Es cierto, lo puedes manejar, pero estás hablando de personas que no se tocan el corazón para acabar con tu familia; incluso los mismos municipales y estatales, y los que andaban ahí de la Federal pidieron discreción absoluta de que no salieran sus rostros ni sus nombres. Ellos mismos que están armados tienen miedo, y ¿qué se espera de nosotros que traemos una cámara?”.

Por ello, en ocasiones, se decide no firmar la nota y acreditarla simplemente como "Redacción" para proteger la identidad del autor, aunque la medida para algunos sea en realidad impráctica, como advierte Conrado Quezada:

"El poner 'Redacción' o 'Especial" en los periódicos es una estupidez, no sirve para maldita sea la cosa. Quienes hacen ese tipo de delitos conocen muy bien al reportero que cubre la fuente, conocen muy bien al vocero de las dependencias, saben muy bien quiénes fueron a cubrir el evento".

\subsection{La empresa y el gremio periodístico}

Es duro el oficio del periodismo en México, y más aún, cuando no se cuenta con condiciones que permitan ejercer en plena libertad y dignidad. Imaginar un panorama en el que los medios de comunicación abogan por una libertad de expresión sin restricciones, y con ello, fomentan entre sus agremiados la búsqueda de información más allá de las fuentes oficiales, es un ideal que ni en sus momentos menos lúcidos, los reporteros locales pueden tener.

Resulta más que lógico creer que los diferentes medios de comunicación brindan lo necesario para que se realicen trabajos de calidad, que cumplan con la función de mantener informado y alerta al ciudadano, ya que en principio, es la razón de ser del medio. Sin embargo, la realidad del día a día de estos profesionales es diferente a la que la sociedad consumidora de información percibe.

César Barragán García ejerce el periodismo en la frontera del estado, donde cotidianamente se ve expuesto a situaciones de riesgo que como ya se ha mencionado, ponen en peligro su vida, y a pesar de que la casa editorial a la que pertenece está al tanto de la situación, se limita a las recomendaciones básicas y los envían a la calle "a la brava".

"Creo que aquí en Nogales todo eso depende de ti, desde que vas a la noticia, toda la cobertura depende de ti. Cuando se trata de algo que puede durar horas, bueno, te respaldan, 
te mandan un compañero, aunque en realidad no importa toda la compañía que te manden y si no se conoce la forma de actuar ante estas situaciones", asegura.

Nos encontramos entonces, ante un deslinde de responsabilidades de las empresas de noticias que permiten cada vez más la superficialidad de la cobertura de la fuente policiaca y que genera la práctica de un periodismo "por encimita", cuando en realidad lo que la sociedad merece son instituciones comprometidas fuertemente con la veracidad del hecho.

En la experiencia de los reporteros que participaron en esta investigación, en más de una ocasión se han encontrado en situaciones de peligro, donde, ante su vulnerabilidad, recurren al sentido común y no al entrenamiento previo que deberían poseer; y si se deja un poco de lado el riesgo de la profesión, el periodismo es un empleo como el de muchos mexicanos, el que además de la pasión y vocación con la que se ejerce, permite el sustento económico de familias de ciudadanos que por ley, deben gozar plenamente del derecho a que las instituciones faciliten los insumos y herramientas de trabajo necesarios para el tipo de actividades que desarrollan.

Por tanto, es necesario valorar la tarea del periodista y garantizar su seguridad mediante:

\subsubsection{La mejora de condiciones laborales}

El periodismo es una profesión de calle en el que se requiere acudir al llamado de los hechos que se presentan. Una cámara, una computadora, una grabadora, son las herramientas fundamentales de trabajo con las que se debe contar, sin embargo no garantizan la seguridad de reporteros y camarógrafos, que son los comisionados en salir a la calle.

Para el quehacer diario se requiere considerar dos aspectos principales: primero, un goce de sueldo proporcional no al salario mínimo, sino al valor de la actividad considerada de alto riesgo, dado que la autonomía económica es un elemento protector.

Y en segundo lugar, también es prioritario el acceso a un medio de transporte propio o de la empresa que le permita conducirse con plena libertad a cualquier momento del día en el que se requiera, ya sea por acudir al acontecimiento mismo, o por trabajos de investigación dentro o fuera de la localidad.

Priscila Cárdenas, una de las pocas reporteras mujer que cubren la fuente policiaca en Sonora, expresa que en ocasiones el factor determinante entre cubrir un evento u otro, se debe a las posibilidades económicas con las que cuenta en ese momento, y aunque le apasiona estar en el lugar de los hechos, prefiere no emplear su salario.

"D esde que estoy en el Expreso (su centro de trabajo), yo voy y cubro a la hora que sea en mi carro. La verdad es que a veces sí me da miedo, y me regreso. O tras veces ni me animo, 
porque aunque es una buena nota, prefiero no arriesgarme a que mi carro se descomponga y me deje tirada, porque en el periódico no me lo van a arreglar".

\subsubsection{Capacitación}

El periodista requiere del dominio y desarrollo de temas de protección y autoprotección, primeros auxilios, atención y tratamiento del estrés postraumático, e incluso de un marco jurídico en que se pueda apoyar en la búsqueda de manifestar su libertad de expresión. Ya no basta solo con talleres de redacción o del manejo de software, ya que saber ordenar y expresar sus ideas correctamente en la nota o dominar las herramientas de edición y diseño, se ha convertido en la menor de las preocupaciones ante el panorama de violencia que se vive en Sonora y en el resto del país.

Conrado Quezada considera que de cierto modo sí existe capacitación y que el problema aquí, es que "la movilidad en el ambiente reporteril es muy volátil, de repente trabajas aquí, luego renuncias para irte para allá, luego de allá te mandan para acá", a lo que propone: "Se necesita manejar un programa que sea constante dentro del medio para que esté quien esté, sea un reportero de toda la vida o un reportero nuevo, tenga la posibilidad de saber. Incluso desarrollar una especie de módulos y decir: 'ya pasé el módulo uno, dos, tres y cuatro, ya no me toca ir a esos, solo le toca a los nuevos'".

Lamentablemente, la posición de un periodista frente una empresa puede ser desechada en cualquier momento, lo que permite mantener un "círculo vicioso" en el que se está al tanto de las condiciones bajo las que se labora, pero que nadie se atreve a denunciar por el miedo latente al reemplazo y con ello la pérdida del ingreso.

\subsubsection{Estar unidos}

Sin duda, hay esfuerzos dignos de reconocimiento en la defensa de la libertad de expresión y del ejercicio periodístico. Sin embargo, desde la perspectiva local, en Hermosillo, Cajeme y Nogales, los comunicadores expresan la falta de unión del gremio, y la evidente necesidad de consolidar grupos con la fuerza suficiente para exigir tanto a los medios de comunicación, como a las autoridades correspondientes.

A nivel nacional e internacional, existen organizaciones de la sociedad civil y no gubernamentales, que defienden y promueven el derecho a la libertad de expresión e información, y que además, consideran que el derecho a la información de una sociedad es un elemento fundamental para la toma de decisiones, y por ello, monitorean, buscan, publican, promocionan y hacen campañas, con el fin de promover esta libertad que se ha visto amenazada. 
Artículo 19, por ejemplo, es una institución que promueve el derecho a prensa mediante acciones de impacto en la sociedad, cuya labor más sobresaliente es el registro de las muertes 0 atentados en contra de periodistas en 51 países del mundo.

Como esta organización que nace a partir de la necesidad de denuncia ciudadana, existen otras que pretenden la unión del gremio en una sola fuerza, de modo que se les permita ser escuchados por el gobierno; sin embargo, a pesar de esfuerzos nacionales como el de la Federación de Asociaciones de Periodistas Mexicanos, A. C. (Feparmex), que actualizó el listado de agrupaciones por última vez en el año 2010, hay desinterés manifiesto hacia la creación de sociedades locales en los diferentes estados de la república.

Cuando se les cuestionó a los reporteros acerca del panorama de las asociaciones periodísticas locales, se mostró tal desinformación que no es tan vago considerar que el gremio no solo está desunido, sino que prefiere mantenerse al margen ante los ataques a compañeros y velar solamente por su propia seguridad.

Algunas agrupaciones, asegura Alfonso Campos Rubio, "son muy elitistas, se agrupan digamos 'los grillos' que cubren gobierno del estado, los columnistas entre ellos, pero a los demás no nos toman en cuenta, no tenemos ninguna base, ningún apoyo con ello, nada. Aquí en Hermosillo desde que yo recuerde no hemos tenido unión por circunstancias de cada quien, además, hay ciertos medios que le prohíben al reportero la unión".

Martín Vallejo González, otra de las instituciones del periodismo en la localidad, señala que "la mayoría de los grupos de periodismo que se forman son para cuestiones de intereses políticos, de intereses personales, más que intereses de verdaderamente velar por el gremio, es la verdad. Se forman grupitos y se entregan reconocimientos mutuamente, pero eso no lleva a nada claro, de decir 'vamos a formar una agrupación de periodistas sin fines políticos, simplemente dirigida a apoyar a los compañeros, a buscar cómo sacarlos adelante, cómo formarlos, llevarlos a cursos, prepararlos'”.

Gustavo Dueñas, editor en jefe del periódico El Valle, platicó que en el sur del estado se han llevado a cabo en los últimos meses, a raíz de fuertes riñas con elementos policiales, reuniones entre periodistas y autoridades municipales y estatales, en las que se ha pretendido el diálogo que permita llegar a acuerdos de beneficio para ambas partes.

"Hubo una reunión con José Larrinaga (ex vocero de la Procuraduría General de Justicia del Estado) y se tocó este tema de nuestra profesión. Sí, nos dedicamos a esto, sabemos a lo que nos vamos a enfrentar. Es como un bombero que se queja ante la sociedad de que se puede quemar en su trabajo, sabe a lo que va desde que eligió ser bombero. Es lo mismo un periodista, sabes a lo que te puedes enfrentar, lo que sí ya no estamos de acuerdo, es cuando la autoridad abusa de su poder y hace uso de eso para atacarnos directamente a nosotros". 
De esta manera, comenta Gustavo, ante las represiones e injusticias cometidas contra ellos, se intentó ejercer un diálogo que de momento parecía ser el inicio de una búsqueda unida del respeto ante la autoridad, pero que se ha quedado solo en un intento más. Es esencial que se considere esta potencial unión del gremio para criterios de autocensura y protección común, o para la solidaridad y seguimiento a temas o figuras comunes que ya no se pueden tocar.

Existen dos temas principales que ya han estado sobre la mesa en círculos periodísticos oficiales, como la Asociación de Periodistas Regionales de Agua Prieta, la del Norte de Sonora, o la del Valle del Yaqui, e incluso en las redes sociales. Por un lado, están quienes piensan que la cobertura informativa de los medios en torno al aspecto del crimen organizado está siendo limitada y aun así se muestran indiferentes, y por el otro hay quienes dicen que los periodistas deben unirse y alzar la voz en conjunto supliendo los esfuerzos individuales de los medios locales más vulnerables a la intimidación del crimen, pero tampoco se determinan acciones.

Por tanto, se considera urgente tomar medidas para fortalecer la independencia de los medios ante el crimen organizado y las autoridades, entre ellas, desarrollar sistemas que fomenten la participación de todo periodista afectado directa o indirectamente, de modo que el reclamo por la seguridad sea escuchado a una sola voz.

\subsubsection{Los retos}

Ante este escenario, hay voces que se expresan, que critican, pero que a la vez, promueven mejores condiciones para el profesional de los medios. "Se necesita un mensaje muy fuerte del gobierno federal, que esto no va a ser tolerado ya. Cuando sea muy claro que hay consecuencias por atacar periodistas o a los medios, entonces esto va a cambiar", señala Lynne Walker (L. Walker, comunicación personal, 6 de septiembre de 2012), quien cuenta con amplia experiencia en el periodismo de investigación y es la actual Coordinadora de Medios del Instituto de las Américas en San Diego. "No hay ninguna nota que valga la vida", añade. "Ninguna. El periodista tiene que cuidarse todo el tiempo, a toda costa. Pero lo que tenemos que hacer también es pensar un poco, encontrar nuevas ideas más creativas para reportar lo que está pasando, sin poner nuestra vida o la de nuestra familia en peligro".

Es muy claro, afirma Conrado Quezada, que es la autoridad quien ha dejado de hacer su trabajo en materia de impartición de justicia, no solo en agresión a comunicadores sino a nivel sociedad, y es esto lo que hace falta para garantizar el libre ejercicio del periodismo. "Que se aplique la ley. Soy un ciudadano normal, un periodista no necesita vigilancia ni cuidado especial; soy un ciudadano que tiene la libertad de meterse donde no le importa y escribirlo. Hay que hacer valer la ley, nadie tiene por qué privarme de mi libertad", enfatiza.

Javier Valdez Cárdenas (J. Valdez, comunicación personal, 25 de enero de 2013), corresponsal de La Jornada, reportero del semanario Río D oce de Culiacán, Sinaloa, y autor de varios libros relacionados con el narcotráfico como Los morros del narco, Miss narco y 
Levantones, sugiere saber contar historias para abordar el fenómeno. "Cubrir el narco, si queremos ser mediocres, es contar muertes. Sí hay que entrarle al tema, pero es mejor publicar historias humanas, porque el silencio es complicidad y muerte, y yo ni estoy muerto ni soy cómplice, por eso le he apostado a contar el narcotráfico desde esta perspectiva".

Entre los esfuerzos a nivel nacional destaca el de Andrés Solís Álvarez (A. Solís, comunicación personal, 26 de octubre de 2012), periodista con más de 20 años de trayectoria, a mediados de 2011 publicó el Manual de autoprotección para periodistas, material basado en entrevistas con policías y militares de varios países, además de libros especializados en seguridad y sus propias experiencias como reportero, con la intención de "aportar un poco entre colegas para que podamos hacer un periodismo con mayor certeza".

Solís Álvarez advierte también la necesidad de cambiar la manera de ejercer la profesión, y de privilegiar los hechos antes que la opinión del gobernador en turno, pues la sociedad lo que necesita es información y comunicadores capacitados, ante lo cual imparte seminarios sobre prevención y reacción ante situaciones de alto riesgo.

Si bien la desaparición de Alfredo Jiménez marca un parteaguas en los medios de comunicación sonorenses, Carlos Moncada (C. Moncada, comunicación personal, 22 de noviembre de 2012) asevera que la falta de investigación periodística viene de mucho tiempo atrás. Moncada O choa, abogado de profesión, escritor y periodista con más de 60 años de trayectoria, señala que con su libro Oficio de muerte, no pretende desalentar sino por el contrario, dejar un mensaje de esperanza, pero entendiendo que es ingenuo pensar que en una fuente como la policiaca, el reportero es inmune al peligro. Puntualiza que no es por medio de legislaciones como se puede enfrentar la situación. "(Al periodista) no se le puede proteger con una ley. Si detienen al homicida, le van a aplicar la ley, pero ya que cometió el delito. No creo que sea cuestión de leyes sino policiaca”, asegura.

No es la misma percepción de Ana Luisa Pacheco Gracia (A. L. Pacheco, comunicación personal, 24 de noviembre de 2012), quien durante más de dos décadas ha ejercido el periodismo de denuncia en radio. Menciona que si bien, un marco legislativo no va a recuperar la vida de nadie, si brinda mayores condiciones de desarrollo democrático, para que cada vez queden menos cabos sueltos para castigar y no haya impunidad cuando se trata de la vida de periodistas.

Ante la situación de veto en los medios de la que Pacheco Gracia aseguró ser víctima del gobierno estatal emergido del Partido Acción Nacional (PAN). Ella representa a la Casa de los Derechos de Periodistas en Sonora, otro de los esfuerzos recientes surgidos con el objetivo de brindar condiciones para llevar a cabo el ejercicio periodístico. A nivel nacional, esta asociación inició en 2010, como una alternativa principalmente a los comunicadores cuya integridad física corre peligro y no reciben la protección de la empresa para la que trabajan, así como para quienes requieren de capacitación en materia de auto protección. 
En paralelo, el organismo busca la unión del gremio a partir de la creación de una iniciativa de ley para el estado de Sonora, como ya se ha implementado en los estados de Colima, Chiapas, Guerrero, Hidalgo y Morelos.

Este marco jurídico se sumaría al recién aprobado D ecreto de la Ley para la Protección de Personas Defensoras de Derechos Humanos y de Federalización de los Delitos cometidos contra Periodistas ${ }^{28}$, que define, entre otros aspectos, la creación del Mecanismo de Protección para personas Defensoras de Derechos Humanos y Periodistas, así como medidas de protección para reducir la exposición al riesgo de comunicadores y activistas, que van desde entrega de equipos hasta evacuación o reubicación temporal.

Así mismo, en abril de 2011 se aprobó para la entidad la Ley de secreto periodístico ${ }^{29}$, la cual reconoce y establece el derecho del periodista a no revelar toda la información o la manera en que ésta ha sido conseguida.

Sin embargo, como suele suceder en este país, las disposiciones jurídicas pueden convertirse en letra muerta si no existe el compromiso de la autoridad en el cumplimiento de las mismas, y para entender el fenómeno como un asunto de prioridad hacia el desarrollo social.

\section{Discusión y conclusiones}

Hasta el momento, los resultados obtenidos producto de la investigación arrojan que en el estado fronterizo de Sonora existe temor por parte del gremio periodístico para la publicación de investigaciones relacionadas con el narcotráfico y la delincuencia organizada, producto de la falta de garantías por parte del Estado mexicano y de las empresas periodísticas.

En Sonora, la cobertura informativa de la fuente policiaca ha cambiado radicalmente en los últimos 10 años; la desaparición de Alfredo Jiménez Mota marcó un "parteaguas" en esta actividad. Para el gremio periodístico quedó claro que a partir de ese momento, era y es imposible hasta la fecha, publicar cualquier información detallada y relacionada con las actividades del crimen organizado en Sonora: nombres de narcotraficantes, rutas de trasiego de la droga o de autoridades coludidas, solo por citar algunos aspectos.

Otro hecho que ha contribuido a esta situación es la "Guerra contra el narcotráfico", la cual después cambió a "Lucha contra la delincuencia organizada", que emprendió Felipe Calderón en su sexenio, con el propósito de combatir a las bandas delictivas que controlan en México diversas actividades ilegales, principalmente lo relacionado al tráfico de drogas.

A lo anterior, también hay que agregar que la reorganización de los cárteles de las bandas criminales, la disputa de éstos por las "plazas", y los lazos de algunas autoridades policiacas 
con la delincuencia organizada, han dejado otro saldo imposible de medir en números: un evidente estado de indefensión de los periodistas para ejercer libre y plenamente el derecho de informar, temor por investigar y publicar datos relacionados con el narcotráfico y, en algunos casos, hasta falta de interés de los mismos periodistas por abordar tales temas; además, pocas oportunidades de capacitación para tratar los mismos y desconocimiento de protocolos de seguridad.

Respecto a la misma autoridad judicial, los reporteros señalan falta de respeto hacia la labor periodística, nula disposición para informar de ciertos acontecimientos violentos; mientras que por el lado del medio de comunicación, no hay un plan de protección para el reportero de la fuente policiaca, se desconoce la dinámica diaria del comunicador y los problemas diarios a los que éste se enfrenta, sin dejar de lado la falta de una organización formal que apoye a los periodistas agredidos, los defienda y alce la voz ante cualquier amenaza 0 agresión.

Por lo anterior, en Sonora no existen las condiciones que garanticen el ejercicio del periodismo policiaco de investigación, es por ello que hoy en día, la información se remite únicamente a datos oficiales que se proporcionan a través de comunicados de prensa 0 voceros de instancias como la Procuraduría General de la República, la Procuraduría G eneral de Justicia del Estado y la Dirección de Seguridad Pública Municipal.

Este panorama ha llevado a los reporteros a ser más cuidadosos en el ejercicio de su labor informativa, desde la manera de reportear hasta el momento de la publicación. Algunos aceptan momentos de censura y autocensura en ambos procesos, otros la llaman inteligencia periodística, pues están conscientes que por ninguna nota vale la pena poner en riesgo su vida e incluso la seguridad de sus familias.

\section{Referencias bibliográficas}

Solís, A. A. (2010). Manual de Autoprotección para Periodistas. México: Publicidad \& Diseño.

Lara, M. \& Barata, F. (2009). Nota(n) roja. M éxico, D.F.: Debate.

Moncada, C. (2012). Oficio de muerte: periodistas asesinados en el país de la impunidad. México: Grijalbo.

Medel, M. (2010). Periodismo en tiempos de amenazas, censura y violencia. Texas: Knight Center.

Knight Center for Journalism in the Americas (2007). Vigilancia y defensa de la libertad de prensa en América Latina y el Caribe. Texas: Knight Center. 
Knight Center for Journalism in the Americas. (2011). Cobertura del narcotráfico y el crimen organizado en Latinoamérica y el caribe.Texas: Knight Center.

World Association of Newspapers and News Publishers. (2012). Una amenaza de muerte a la libertad: Informe sobre la violencia contra la prensa en M éxico. WAN-IFRA.

\section{Notas}

${ }^{1}$ Agencias. (2012, 19 de noviembre). Calderón deja a México con más muertes que la guerra de Irak. Vanguardia. Recuperado de http://www.vanquardia.com.mx/calderondejamexicoconmasmuertesquelaquerradeirak1428232.html

${ }^{2}$ Redacción / Sin embargo (2013, 14 de febrero). Sexenio de Felipe Calderón, el más violento que ha existido para la prensa en el mundo: CPJ. Sin embargo. Recuperado de: www.sinembargo.mx/14-02-2013/528262

${ }^{3}$ Riva, R. (2013). Manual para un nuevo periodismo. Desafíos del oficio en la era digital. México: Grijalbo.

${ }^{4}$ Ríos, Viridiana (13 de junio de 2014). Tendencias y explicaciones al asesinato de periodistas y alcaldes en México: El crimen organizado y la violencia de alto perfil [Mensaje en un blog]. Recuperado de: http://viridianarios.com/2014/06/the-assasination-of-journalits-and-mayors-inmexicos-druq-war-2012-in-spanish/

Rodelo, Frida. Periodismo en entornos violentos: el caso de los periodistas de Culiacán, Sinaloa. Comunicación y Sociedad [en línea]. Jul./dic. 2009, no 12 [fecha de consulta: 5 de noviembre de 2015]. Disponible en: http://scielo.unam.mx/scielo.php?pid=S0188252X2009000200005\&script=sci arttext

${ }^{5}$ Reporteros sin fronteras. 2012: Periodistas asesinados. Barómetro de la libertad de prensa. Recuperado de http://en.rsf.org/press-freedom-barometer-journalists-killed.html?annee=2012

${ }^{6}$ Campaña Emblema de Prensa. Llama PEC al gobierno mexicano detener matanza de periodistas y respaldar la Ley de Protección. Recuperado de http://www.pressemblem.ch/10399.html

${ }^{7}$ Article 19. Silencio Forzado, el Estado cómplice de la violencia contra la prensa, 2011. Londres, Inglaterra. Recuperado de http://www.articulo19.org/portal/index.php?option=com content\&view=article\&id=277:inform e-anual-2011

${ }^{8}$ Higa. D (2013, 11 de febrero). La (des) protección de periodistas en México. Recuperado de http://mx.ibtimes.com/articles/31066/20130211/proteccion-periodistas-mexico-ley.htm

${ }^{9}$ (2012, 14 de junio) CNDH Denuncia que van 82 periodistas asesinados desde 2000. Terra Noticas. Recuperado de http:// noticias.terra.com.mx/mexico/seguridad/cndh-denuncia-que-van82-periodistas-asesinados-desde-2000,20425d71ddde7310VgnVCM 20000099cceb0aRCRD.html

${ }^{10}$ Federación Latinoamericana de Periodistas. Informe actualizado sobre la situación del periodismo en México anualizado enero-diciembre 2011. Recuperado de http://www. actualidadesmexico.mx/2012/01/informe-actualizado-sobre-la-situacion-delperiodismo-en-mexico-anualizado-a-2011/

${ }^{11}$ Moncada, C. (2012). Oficio de muerte. Periodistas asesinados en el país de la impunidad. México: Grijalbo.

12 Reporteros sin fronteras. Hecatombe para los actores de la información. Recuperado de http://es.rsf.org/2012-hecatombe-periodistas-netciudadanos-19-12-2012,43814.html

${ }^{13}$ Nateras C. (2013, 16 de enero). El Estado actúa ante la problemática que enfrenta el periodismo. Recuperado de http://revistaradical. $\mathrm{mx} / \mathrm{p} \mathrm{p}=3274$

14 Bolaños, B. et al. (2010). Acercamientos a la libertad de expresión. Diez visiones multidisciplinarias. México: Bosque de letras.

${ }^{15}$ Blancornelas, J. (2005). En estado de alerta. Los periodistas y el gobierno frente al narcotráfico. México: Random House M ondadori.

${ }^{16}$ Solís, A. (2011). Manual de Autoprotección para periodistas. México: Autor. 
${ }^{17}$ Lara, M. y Barata, F. (2009). Nota roja. La vibrante historia de un género y una nueva manera de informar. M éxico: Debate.

${ }^{18}$ De León, Salvador. Agresiones en contra de periodistas en México: estudio de las acciones de los colectivos en red. Memorias del XXVI Encuentro Nacional AMIC, San Luis Potosí 2014 [en línea]. Mayo de2014 [fecha de consulta: 5 de noviembre de 2015]. Disponible en: http://amic2014.uaslp.mx/q5/g5 13.pdf

${ }^{19}$ Riva, R. (2004). La prensa de los jardines. Fortalezas y debilidades de los medios en México. México: Random House M ondadori.

${ }^{20}$ Flores, B., Gómez, P., M artínez, O. y Gallardo, A. (2008). Análisis y testimonios de la libertad de expresión en México. México: Fundación Manuel Buendía.

${ }^{21}$ Gómez, P. (2011) et al. Libertad de expresión. Cuaderno de trabajo. México: Bosque de letras.

${ }^{22}$ Gomez, P. et al. (2010). Compromiso con la libertad de expresión. Análisis y alcances. México: Fundalex.

${ }^{23}$ Rodelo, Frida. Periodismo en entornos violentos: el caso de los periodistas de Culiacán, Sinaloa. Comunicación y Sociedad [en línea]. Jul./ dic. 2009, oo 12 [fecha de consulta: 5 de noviembre de 2015]. Disponible en: http://scielo.unam. mx/scielo.php?pid=S0188$252 \times 2009000200005 \&$ script $=$ sci arttext

${ }^{24}$ Martínez, R. (2008). Informe Buendía 2007. Análisis hemerográfico sobre los obstáculos a la libertad de expresión en México. México: Fundación Manuel Buendía.

${ }^{25}$ González, Silvia. Periodismo en M éxico: entre la guerra contra el narcotráfico y la defensa de los derechos humanos. Congreso Iberoamericano de Comunicación 2011 [en línea]. Noviembre de 2011. [fecha de consulta: 5 de noviembre de 2015]. Disponible en: http://www.imultimedia.pt/ibercom/comunicacoes/ibercom2011/comunica ibercom en pdf/P onencias\%20GT1\%20Periodismo/ponencia\%20GT1 Gonzalez.pdf

${ }^{26}$ Gómez, F. (2006, 26 de enero). Integran periodistas Proyecto Fénix. El Universal. Recuperado de http:// www.eluniversal.com.mx/notas/327616.html

${ }^{27}$ NOTA DELEDITOR: La nota roja hace mención a la noticia de sucesos.

${ }^{28}$ Olson, G. y Notimex (2012, 23 de junio). Calderón decreta proteger a periodistas y defensores de derechos humanos. Excélsior. Recuperado de http://www.excelsior.com.mx/2012/06/23/nacional/842997

${ }^{29}$ Gallegos, Zorayda (2011, 13 de abril). Sonora aprueba Ley de secreto periodístico. El Universal. Recuperado de http://www.eluniversal.com.mx/notas/758976.html 


\section{(c) (i) (2) \\ Licencia Creative Commons \\ Miguel Hernández Communication Journal \\ mhcj.es}

\section{Forma de citar este artículo en las bibliografías}

Joaquín Andrés Félix Anduaga,. Eliana Alvarado Noriega y Lin Mendívil Alvarado (2015): "Censura y autocensura en la cobertura de temas relacionados al narcotráfico y la delincuencia organizada en el Estado de Sonora, México”, en Miguel Hemández Communication Journal, nº6, páginas 129 a 160. Universidad Miguel Hernández, UMH (Elche-Alicante). Recuperado el _- de de 20 _de: [link del artículo en mhjournal.org] 